\title{
Biocontrol of Late Blight (Phytophthora capsici) Disease and Growth Promotion of Pepper by Burkholderia cepacia MPC-7
}

\author{
Mao Sopheareth', Sarun Chan', Kyaw Wai Naing ${ }^{2}$, Yong Seong Lee ${ }^{2}$, Hae Nam Hyun ${ }^{3}$, Young Cheol Kim² \\ and Kil Yong $\mathrm{Kim}^{2 *}$ \\ ${ }^{1}$ Ministry of Agriculture, Forestry and Fisheries, Phnom Penh, Cambodia \\ ${ }^{2}$ Institute of Environmentally-Friendly Agriculture, College of Agriculture and Life Sciences, Chonnam National University, \\ Gwangju 500-757, Korea \\ ${ }^{3}$ Major of Plant Resources and Environment, Jeju National University, Jeju 690-756, Korea \\ (Received on July 24, 2012; Revised on November 8, 2012; Accepted on December 9, 2012)
}

\begin{abstract}
A chitinolytic bacterial strain having strong antifungal activity was isolated and identified as Burkholderia cepacia MPC-7 based on 16S rRNA gene analysis. MPC7 solubilized insoluble phosphorous in hydroxyapatite agar media. It produced gluconic acid and 2-ketogluconic acid related to the decrease in $\mathrm{pH}$ of broth culture. The antagonist produced benzoic acid (BA) and phenylacetic acid (PA). The authentic compounds, BA and PA, showed a broad spectrum of antimicrobial activity against yeast, several bacterial and fungal pathogens in vitro. To demonstrate the biocontrol efficiency of MPC-7 on late blight disease caused by Phytophthora capsici, pepper plants in pot trials were treated with modified medium only (M), M plus zoospore inoculation (MP), MPC-7 cultured broth (B) and B plus zoospore inoculation (BP). With the sudden increase in root mortality, plants in MP wilted as early as five days after pathogen inoculation. However, plant in BP did not show any symptom of wilting until five days. Root mortality in BP was markedly reduced for as much as $50 \%$. Plants in $B$ had higher dry weight, $P$ concentration in root, and larger leaf area compared to those in $M$ and MP. These results suggested that $B$. cepacia MPC-7 should be considered as a candidate for the biological fertilizer as well as antimicrobial agent for pepper plants.
\end{abstract}

Keywords : antimicrobial activity, biological fertilizer, phosphate solubilization, root mortality, zoospore

Pepper (Capsicum annuum L.) is an important vegetable crop in Korea (Chae et al., 2005). Phytophthora blight of pepper, which is caused by Phytophthora capsici is one of the most devastating soilborne diseases of pepper in Korea

\footnotetext{
*Corresponding author.

Phone) +82-62-530-2126, FAX) +82-62-530-2139

E-mail)kimkil@chonnam.ac.kr
}

(Hwang and Kim, 1995), India, United States and other pepper growing areas worldwide (Babu et al., 2011). This soilborne pathogen can infect all parts of the pepper plant via water splashing from the soil to the foliage and can rapidly disperse in surface water (Ristaino and Johnston, 1999). The chemical and cultural measures cannot always control persistent propagules such as $P$. capsici oospores (Lamour and Hausbeck, 2003). Moreover, their efficiency is decreased due to evolution of resistance by the pathogen (Rosenberger and Meyer, 1981) and the use of synthetic chemicals can also kill useful soil insects and beneficial microorganisms in the rhizosphere (Bartlett et al., 2002).

Several species of bacteria are known to have beneficial effect on plant growth and disease suppression through the production of plant growth-promoting regulators and antibiotic substances (Ren et al., 2011). One of the direct mechanisms that promote plant growth by the plant growth promoting rhizobacteria (PGPR) includes the provision of bioavailable nutrient for plant uptake (Richardson, 2001). On the other hand, indirect growth promotion occurs through the decrease or prevention of deleterious effect of pathogenic microorganisms, mostly due to antagonism (OrtegaMorales et al., 2009) and the synthesis of antibiotics (Sivan et al., 1992).

Supplying $\mathrm{P}$ for plant uptake through biological means is a viable alternative (Kim et al., 1998). Solubilization of phosphorus in rhizosphere is the most common mode of action implicated in PGPR that increase the nutrient availability to the host plant (Richardson, 2001). Particularly, phosphate-solubilizing bacteria (PSB) solubilize the insoluble inorganic $\mathrm{P}$ by producing organic acids (Leyval and Berthelin, 1989). These organic acids can either directly dissolve the mineral phosphates as a result of anion exchange or can chelate both $\mathrm{Fe}$ and $\mathrm{Al}$ ions associated with phosphate (Bajpai and Rao, 1971). The organic acids involved in phosphate solubilization include oxalic, citric, butyric, malonic, lactic, succinic, malic, gluconic, acetic, 
glyconic, fumaric, adipic, and 2-ketogluconic acid (Kim et al., 1998; Sperber, 1957). Among them, gluconic acid seems to be the most frequent agent for mineral $\mathrm{P}$ solubilization (Illmer and Schimmer, 1992) and it is produced by direct oxidation of glucose via membrane-bound quinoprotein GDH enzyme (Patel et al., 2008). In addition, Moghimi et al. (1978) reported that 2-ketogluconic acid was the only organic acid present in significant amounts, representing about 20 per cent of the rhizosphere products. The microbial simulated P solubilization simultaneously increases the $\mathrm{P}$ uptake and yield in many crops as demonstrated in tomato, potato, rice, sugar beet and citrus with Pseudomonas fluorescens (Kloepper et al., 1988), potato with Bacillus spp. (Burr et al., 1978), and wheat with Azospirillum spp. (Baldani et al., 1986).

Antibiotics to pathogen growth suppression have been isolated from a number of bacterial species such as Burkholderia ambifaria (Li et al., 2002) and Pseudomonas spp. (Paul and Sarma, 2006). The distinguished antibiotic productions such as pyrrolnitrin, pyoluteorin and 2,4diacetylphloroglucinol by Pseudomonas fluorescens Pf-5 (Loper et al., 2007) and various antifungal lipopeptides by Bacillus amyloliquefaciens FZB42 (Koumoutsi et al., 2004) have been previously reported. Weak acids such as benzoic acid are used to preserve foods and beverages. Once they enter the neutral $\mathrm{pH}$ of the cytoplasm, they dissociate to release an anion and a proton. The $\mathrm{pH}$ gradient across the plasma membrane drives the intracellular accumulation of protons and anions, reducing the intracellular $\mathrm{pH}$ and inhibiting the growth of the micro-organism (Booth and Kroll, 1989).

In this experiment, we focused to isolate a multifunctional strain producing organic acids and antimicrobial compounds during bacterial growth and tested its practical application on pepper in pot trial. Therefore, the objectives of this investigation were to isolate a strain that had both strong phosphate solubilizing and disease suppressing activities; to extract and identify the antimicrobial compounds; to determine the biological activities of isolated compounds in vitro, and to investigate the biocontrol efficiency of the new isolate on Phytophthora blight disease on pepper in vivo.

\section{Materials and Methods}

Isolation of bacterial strain. Soil samples collected from pepper fields of Naju area, Korea, were serially diluted with sterile water up to $10^{-6}$ times and $100 \mu \mathrm{l}$ of soil suspension was spread on the surface of chitin media (CM) (wt/vol; chitin $0.5 \% ; \mathrm{Na}_{2} \mathrm{HPO}_{4} 0.2 \% ; \mathrm{KH}_{2} \mathrm{PO}_{4} 0.1 \%$; $\mathrm{NaCl} 0.05 \%$; $\mathrm{NH}_{4} \mathrm{Cl} 0.1 \%$; $\mathrm{MgSO}_{4} \cdot 7 \mathrm{H}_{2} \mathrm{O} 0.05 \%$; $\mathrm{CaCl}_{2} \cdot 2 \mathrm{H}_{2} \mathrm{O} 0.05 \%$; $\mathrm{KNO}_{3} 0.05 \%$; yeast extract $0.01 \%$; and agar $2 \%$; $\mathrm{pH} 7$ ).
After five days incubation at $30^{\circ} \mathrm{C}$, the strains which showed the halo zones were selected and checked for the antifungal activity against Phytophthora capsici, Rhizoctonia solani AG-1 (IA), and Fusarium oxysporoum f. sp lycopesici by dual culturing method on the $\mathrm{CP}$ media which was composed of $50 \%$ of chitin media (CM) and $50 \%$ of potato dextrose agar media (PDA). Finally, the strongest strain against all three fungal pathogens was selected. The bacterium was cultured in a 500-ml Erlenmeyer flask containing $200 \mathrm{ml} \mathrm{LB}$ broth (Luria Bertani, Detroit, MI) and incubated for 5 days at $28^{\circ} \mathrm{C}$ on a rotary shaker. The broth culture was then cryopreserved at $-75^{\circ} \mathrm{C}$ in $50 \%$ (vol/ $/ \mathrm{vol}$ ) glycerin until further use (Sopheareth et al., 2006).

Identification of bacterial strain. The 16S rRNA gene analyses were performed directly using a single colony of the strain MPC-7 isolate, according to the procedure described by Di Cello (1997). The forward primer was 5'TGGCTCAGAAGCAACGCTGGCGGC-3', and the reverse primer was 5'-CCCACTGCTGCCTCCCGTAGGAGT-3'. The temperature cycle was at $94^{\circ} \mathrm{C}$ for $30 \mathrm{~s}, 55^{\circ} \mathrm{C}$ for $1 \mathrm{~min}$, and $72^{\circ} \mathrm{C}$ for $1 \mathrm{~min} 30 \mathrm{~s}$ for 30 cycles and $5 \mathrm{~min}$ at $72^{\circ} \mathrm{C}$ for extension. The polymerase chain reaction product was cloned using pGEM-T easy vector (Promega, Madison, WI). The nucleotide sequence of the 16S rRNA gene was determined by Biodye Terminator cycle sequencing kit and compared with published 16S rRNA sequences using Blast search at Gene Bank Data base of NCBI (Bethesda, MD).

Phosphate solubilization and measurement of organic acid produced by B. cepacia MPC-7. The selected strain was checked for its phosphate solubilizing activity on hydroxyapatite agar (HA) medium [wt/vol; $\mathrm{Ca}_{10}(\mathrm{OH})_{2}\left(\mathrm{PO}_{4}\right)_{6}$ $0.4 \% ; \mathrm{NaCl} 0.1 \% ; \mathrm{MgSO}_{4} \cdot 2 \mathrm{H}_{2} \mathrm{O} \quad 0.04 \% ; \mathrm{CaCl}_{2} \cdot 2 \mathrm{H}_{2} \mathrm{O}$ $0.02 \% ; \mathrm{KCl} 0.02 \%$; yeast extract $0.02 \%$; yeast autolysate $0.02 \%$; tryptone peptone $0.02 \%$ and agar $1.5 \%, \mathrm{pH} 7]$. After incubation at $30^{\circ} \mathrm{C}$ for three days, the appearance of clear zone around the colony was observed.

For the measurement of organic acid production, the selected strain was grown in culture broth (CB) containing colloidal chitin $0.5 \%$; hydroxyapatite $0.4 \%$; glucose $1 \%$; $\mathrm{NH}_{4} \mathrm{Cl} 0.1 \% ; \mathrm{NaCl} 0.05 \% ; \mathrm{MgSO}_{4} \cdot 7 \mathrm{H}_{2} \mathrm{O} 0.05 \% ; \mathrm{CaCl}_{2}$ $2 \mathrm{H}_{2} \mathrm{O} 0.05 \%$; $\mathrm{KNO}_{3} 0.05 \%$; yeast extract $0.01 \%$ and $\mathrm{pH} 7.0$ at $30^{\circ} \mathrm{C}$ and $170 \mathrm{rpm}$ for 5 days. Broth culture was filtered through a Whatman $0.2 \mu \mathrm{m}$ membrane filter. Organic acids in filtrate were determined by high performance liquid chromatography (HPLC) (Shimadzu, Japan) with Shodex RSpak KC-811 column $(8 \mathrm{~mm} \times 30 \mathrm{~cm})$. The operating conditions consisted of $0.1 \% \mathrm{H}_{3} \mathrm{PO}_{4}$ as the mobile phase, a constant flow rate of $0.5 \mathrm{ml} \mathrm{min}{ }^{-1}$, and sample injection of $20 \mu \mathrm{l}$ under the UV $210 \mathrm{~nm}$. The organic acids were quantitatively determined by comparing peak areas of 
chromatograms with those of authentic standards.

Measurement of changes in $\mathrm{pH}$ and $\mathrm{P}$ concentration of the culture media. The $\mathrm{pH}$ and $\mathrm{P}$ concentrations in the same culture broth (CB) were also measured every $24 \mathrm{~h}$. The $\mathrm{pH}$ of broth culture was measured directly by immersing the probe of $\mathrm{pH}$ meter into culture solution. To measure $\mathrm{P}$ concentration, the supernatant was filtered through Whatman No.6 filter paper. Fifty microliter of filtrate was poured into a $20 \mathrm{ml}$ test tube containing $1.95 \mathrm{ml}$ extracting solution. Then, $5 \mathrm{ml}$ of distilled water, $2 \mathrm{ml}$ of $12 \mathrm{mM}$ ammonium paramolybdate solution and $1 \mathrm{ml}$ of $5 \mathrm{mM}$ $\mathrm{SnCl}_{2}$ were added and mixed well. After incubation for 5 minutes, the concentration of $\mathrm{P}_{2} \mathrm{O}_{5}$ was measured spectrophotometrically at $660 \mathrm{~nm}$ (Olsen and Sommers 1982).

Extraction, identification and elucidation of antimicrobial compounds. MPC-7 was grown in $\mathrm{CB}$ at $30^{\circ} \mathrm{C}$ on a rotary shaker for $96 \mathrm{~h}$. The culture broth was centrifuged at 6000 rpm for $10 \mathrm{~min}$ at $4{ }^{\circ} \mathrm{C}$. The supernatant was acidified with $1 \mathrm{~N} \mathrm{HCl}$ to $\mathrm{pH} 3$ and extracted with an equal volume of ethyl acetate (EtOAc, 15-L three times). The EtOAc soluble organic fraction was concentrated under vacuum using a rotary evaporator (Büchi, Switzerland). Then, the ethylacetate soluble organic fraction $(0.4 \mathrm{~g})$ was loaded on
Sephadex LH-20 column chromatography. The active fraction (102 mg) was further purified by octadecylsilane (ODS) column chromatography with $\mathrm{MeOH}-\mathrm{H}_{2} \mathrm{O}$ as stepwise and an active fraction was dissolved at $60 \% \mathrm{MeOH}(5.4 \mathrm{mg})$. Finally, two active peaks from HPLC analysis were further identified by GC-EI-MS.

Microorganisms. Bacterial and fungal pathogens used in this assay were purchased from Korean Agricultural Culture Collection (KACC) and Korean Collection for Type Cultures (KCTC) in Suwon, South Korea (Table 1).

Bactericidal activity assay. The antimicrobial assay was conducted on sterile petri plates $(91 \mathrm{~mm})$ containing $20 \mathrm{ml}$ of $1.5 \%$ nutrient agar (Lam et al., 2000). An aliquot of $50 \mu 1$ of bacterial inoculum containing $10^{8} \mathrm{cfu} \mathrm{ml}^{-1}$ was added to $20 \mathrm{ml}$ of nutrient broth medium plus 1.5\% Bacto agar cooled at $45^{\circ} \mathrm{C}$. This medium was then poured into petri dishes, and maintained for $1 \mathrm{~h}$ at room temperature. Sterile paper discs were loaded with $10 \mu \mathrm{l}$ of each benzoic acid and phenylacetic acid purchased from Sigma-Aldrich Chemical Company in methanol dilutions to a known concentration (500 ppm). After drying, six discs including one methanolimpregnated negative control were placed on the surface of each agar plate. A transparent ring around the paper disk

Table 1. The inhibition diameter of 500 ppm benzoic acid (BA) and phenylacetic acid (PA) against yeast and plant pathogenic bacteria after $24 \mathrm{~h}$ of incubation at $30^{\circ} \mathrm{C}$ or $37^{\circ} \mathrm{C}$ and the degree of inhibition against filamentous fungi 5 days after incubation at $26^{\circ} \mathrm{C}$

\begin{tabular}{|c|c|c|c|}
\hline \multirow{2}{*}{ Microorganisms } & \multirow{2}{*}{ Strain Identification } & \multicolumn{2}{|c|}{ Growth Inhibition } \\
\hline & & BA & PA \\
\hline \multicolumn{4}{|l|}{ Bacteria } \\
\hline Agrobacterium tumefaciens & KACC $^{\mathrm{a}} 10298$ & $15.2 \pm 0.2$ & $15.3 \pm 0.2^{*}$ \\
\hline Escherichia coli & $\mathrm{KCTC}^{\mathrm{b}} 2593$ & $13.7 \pm 0.2$ & $15.7 \pm 0.3$ \\
\hline Micrococcus luteus & КСТC 3523 & $11.2 \pm 0.2$ & $11.0 \pm 0.3$ \\
\hline Pseudomonas aeruginosa & KCTC 2513 & $12.5 \pm 0.3$ & $12.3 \pm 0.2$ \\
\hline Staphylococcus aureus & КСТC 1928 & $13.0 \pm 0.3$ & $12.3 \pm 0.2$ \\
\hline Xanthomoas campestris pv. vesicatoria & KACC 11157 & $17.3 \pm 0.3$ & $16.2 \pm 0.2$ \\
\hline \multicolumn{4}{|l|}{ Yeast } \\
\hline Saccharomyces cerevisia & KACC 7904 & $13.7 \pm 0.2$ & $11.2 \pm 0.2$ \\
\hline \multicolumn{4}{|l|}{ Fungi } \\
\hline Alternaria brassicicola & KACC 40034 & \pm & \pm \\
\hline Botrytis cinerea & KACC 40573 & ++ & \pm \\
\hline Didymella bryoniae & KACC 40900 & ++ & + \\
\hline Fusarium oxysporum f. sp gladioli & KACC 40051 & ++ & \pm \\
\hline Fusarium oxysporum f. sp melonis & KACC 40904 & + & - \\
\hline Phytophthora capsici & KACC 40483 & ++ & ++ \\
\hline Pythium aphanidermatum & KACC 40156 & ++ & ++ \\
\hline Rhizoctonia solani AG-1 & KACC 40111 & ++ & ++ \\
\hline
\end{tabular}

${ }^{a}$ Korean Agricultural Culture Collection (KACC); ${ }^{b}$ Korean Collection for Type Cultures (KCTC), ${ }^{*}$ Each value is the mean of inhibition diameter in millimeter from three replicates $( \pm \mathrm{SD})$; the fungal growth inhibition was reported as $(-)$ between 30 and $45 \%$; $( \pm)$ between 45 and $60 \%$; $(+)$ between 60 and $80 \%$; and $(++) 100 \%$. 
signified antibacterial activity (Wang et al., 2001) and the diameter of the inhibition zone was measured after $24 \mathrm{~h}$ at $30^{\circ} \mathrm{C}$ or $37^{\circ} \mathrm{C}$ depending on optimal temperature requirements for growth of the particular bacterium.

Antifungal activity assays. The in vitro antifungal activity of benzoic acid and phenylacetic acid purchased from Sigma-Aldrich Chemical Company was assessed on basis of hyphal radial growth rate of filamentous fungi. The assay was performed by placing an 8-mm diameter plug of growing mycelia onto the center of PDA containing 500 ppm of each compound. Control plates were prepared with $500 \mathrm{ppm}$ of methanol only. The radial growth of mycelia (colony diameter) was measured 5 days after inoculation at $26^{\circ} \mathrm{C}$. The percentage of growth inhibition was calculated from the formula used by Chilpa et al. (1997).

$\%$ Inhibition $=(\mathrm{A}-\mathrm{B}) / \mathrm{A} \times 100$,

where $\mathrm{A}=$ mycelia growth in control, and $\mathrm{B}=$ mycelia growth in PDA containing active compound.

Destruction of $P$. capsici hyphal morphology by antifungal compounds. The virulent pathogen, $P$. capsici (KACC 40483) was grown on V8 juice media and zoospore suspension was prepared to get a final concentration of $5 \times 10^{5}$ zoospores $/ \mathrm{ml}$ (Kim et al., 1997). Twenty microliters of fungal spores were placed into plate wells containing $180 \mu \mathrm{l}$ of potato dextrose broth and incubated at $30^{\circ} \mathrm{C}$ in orbital incubator for $24 \mathrm{~h}$. The benzoic acid and phenyl acetic acid were dissolved individually in methanol and added into each well to a final concentration of 250 ppm. Wells containing only potato dextrose broth and methanol were set as control. After $24 \mathrm{~h}$ of interaction, the growth inhibition was determined by observing the morphology of hyphae under the microscope (BX41, Olympus, Japan).

Biocontrol of $P$. capsici by B. cepacia MPC-7 on pepper in vivo. Four weeks old seedlings of pepper (Capsicum annuит L.) were transplanted to pots containing $600 \mathrm{~g}$ of potting mixture (soil:sand:vermiculite, 2:1:1, vol:vol:vol). Plant growth room was set to $24^{\circ} \mathrm{C}$, artificial illumination of 12,000 lux at plant height and $16 \mathrm{~h}$ photoperiod. Treatments were $\mathrm{CB}$ medium only (M), $\mathrm{M}$ plus zoospore inoculation (MP), MPC-7 cultured broth (B) and B plus zoospore inoculation (BP). Treatments were arranged in completely randomized design with three replications. One hundred fifty milliliters of bacterial suspension $\left(3 \times 10^{9}\right.$ colony $\mathrm{ml}^{-1}$ ) was inoculated three times at 5, 6 and 7 weeks after transplanting (WAT) to B and BP treatments while $\mathrm{M}$ and MP were applied with same volume of $\mathrm{CB}$ medium only. The zoospore suspension of $P$. capsici (KACC 40483) previously grown on V8 juice media was prepared to get a final concentration of $5 \times 10^{5}$ zoospores per one milliliter (Kim et al., 1997). At 8 WAT, $50 \mathrm{ml}$ of zoospore suspension was inoculated to the soil after punching four holes to the soil $4 \mathrm{~cm}$ from the base of the stem. Only water was applied to control pots in $\mathrm{M}$ and $\mathrm{B}$. Destructive samplings were done at $0,1,3,5,7$ and 9 days after pathogen inoculation. Roots were carefully washed and the fresh weight was measured after blot drying. Dry weights of both shoots and roots were measured after drying at $65^{\circ} \mathrm{C}$ for $48 \mathrm{~h}$. The micro-kjedahl method was used for $\mathrm{N}$ determination (Chapman, 1961). The phosphorous concentration of root and shoot was determined by UV spectrophotometer by the method of John et al. (1991). Root mortality was measured using the modified method of Knievel (1973).

Statistical analysis. Experimental data were analyzed using standard analysis of variance (ANOVA) followed by Least Significant Difference tests $(p<0.05)$ using software statistical analytical system (SAS) 9.12 version (SAS Institute Inc, 2008). Standard errors were calculated for all mean values.

\section{Results}

Identification of isolated bacteria. Twenty unknown strains showed chitinolytic activities on CM. Among them, one strain having the strongest antifungal activity on dual culture with three fungal pathogens was selected (data not shown). Alignment of 16S rRNA gene sequence through matching with reported 16S rRNA gene sequences using Blast search at Gene Bank Data base of NCBI (Bethesda, MD) showed $100 \%$ similarity to Burkholderia cepacia strains (GenBank accession number: AF311970, AF097532, AY741337, AB114607, AY946010 and AY946011) and this strain was named as Burkholderia cepacia MPC-7.

Phosphate solubilization and organic acid production by MPC-7. MPC-7 solubilized the insoluble phosphate and showed distinct clear zone around the colony in hydroxyapatite agar (HA) media (data not shown). Production of organic acids in culture broth (CB) by MPC-7 was measured by HPLC analysis and it revealed two major peaks which were further identified as gluconic acid and 2-ketogluconic acid. The changes of these organic acid concentrations in the nutrient broth media were monitored as shown in Fig. 1. One day after incubation, the concentrations of gluconic acid and 2-KGA were the same around $1,000 \mathrm{ppm}$. The concentration of 2-KGA, however, increased continuously to the end of experiment up to $5,580 \mathrm{ppm}$. On the other hand, the concentration of gluconic acid remained stable around 1,000 ppm. 


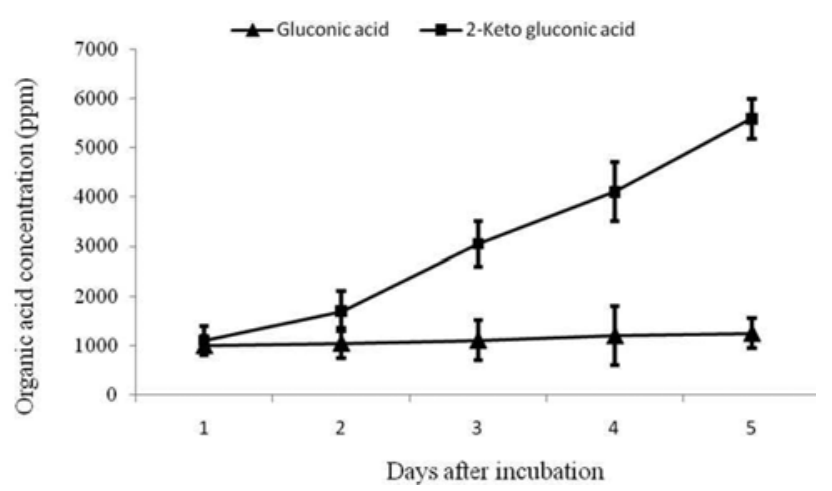

Fig. 1. Changes in concentration of organic acids at chitin medium (CM) containing $0.4 \%$ of hydroxyapatite grown with $B$. cepacia $\mathrm{MPC}-7$ at $30^{\circ} \mathrm{C}$ for 5 days. Mean values were from three replicates $( \pm \mathrm{SD})$.

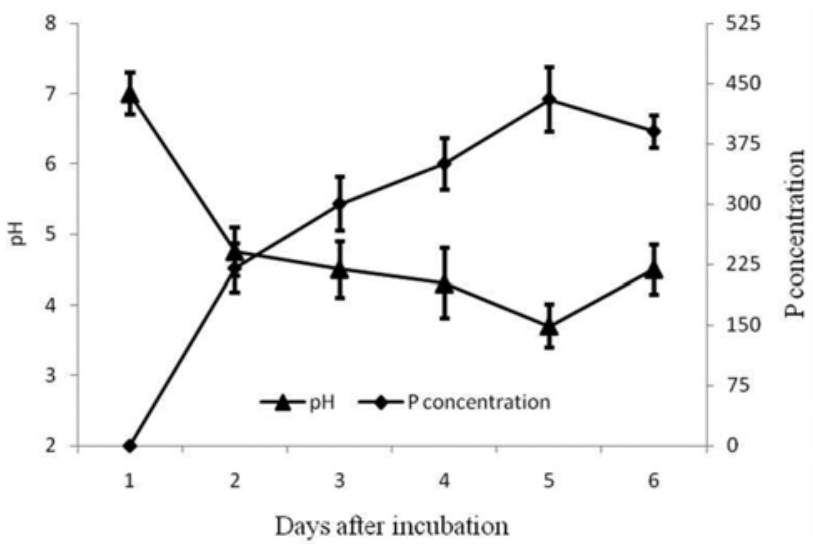

Fig. 2. Changes in $\mathrm{pH}$ and $\mathrm{P}$ concentrations at chitin medium (CM) containing $0.4 \%$ of hydroxyapatite grown with $B$. cepacia MPC-7 at $30^{\circ} \mathrm{C}$ for 6 days. Mean values were from three replicates $( \pm \mathrm{SD})$.

Measurement of changes in $\mathrm{pH}$ and $\mathrm{P}$ concentration of the culture media. The $\mathrm{pH}$ value had an inverse correlation with the quantity of soluble phosphate. The initial $\mathrm{pH}$ of the culture broth set to 7.0 declined sharply to 4.5 (Fig. 2) one day after incubation with MPC-7 and was gradually decreasing thereafter. The maximum concentration of soluble phosphate $(430 \mathrm{ppm})$ was measured after four days of incubation when the $\mathrm{pH}$ declined to the minimum (3.7). Similarly, a moderate increase in $\mathrm{pH}$ of the culture broth at the last observation correlated to a corresponding decrease in organic acid production.

Extraction, identification and elucidation of antimicrobial compounds. The ethyl acetate-soluble organic fraction $(0.4 \mathrm{~g})$ subjected to Sephadex LH-20 column chromatography produced activity at Ve/Vt of 0.86 to $0.92(102 \mathrm{mg})$. After purifying this active fraction by ODS column chromatography, an active fraction at $60 \% \mathrm{MeOH}$ eluate

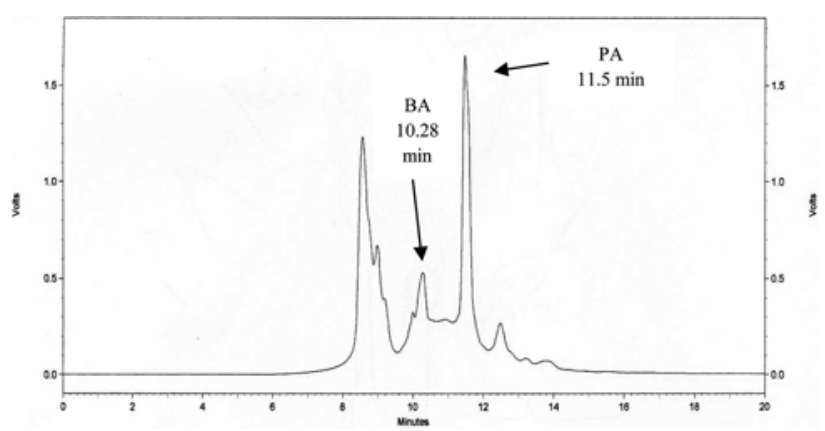

Fig. 3. Typical HPLC chromatogram showing the active peaks of benzoic acid and phenylacetic acid isolated from the culture of $B$. cepacia MPC-7.

(5.4 mg) was obtained. HPLC analysis of the active compound separated into two active peaks with retention times $\left(t_{R}\right)$ of $10.28 \mathrm{~min}$ and $11.5 \mathrm{~min}$ (Fig. 3). Each compound was identified by GC-EI-MS and determined as benzoic acid (BA) and phenylacetic acid (PA), respectively (Figs. 4A and 4B). They were also confirmed by trimethylsilylation and GC-EI-MS as trimethylsilyl benzoate and trimethylsilyl phenylacetate (data not shown).

Antimicrobial activities of benzoic acid (BA) and phenylacetic acid (PA). Both BA and PA showed distinct clear zones against all types of bacteria tested in this experiment and the inhibition diameter ranged from 11.0 to $17.3 \mathrm{~mm}$ at $500 \mathrm{ppm}$ (Table 1). The strongest antibacterial activities of BA and PA in term of wider clearance zones (17.3 and 16.2, respectively) were observed against $X$. campestris pv. vesicatoria. Similarly, the growth inhibition of S. cerevisiae (yeast) was also observed for having the wider clear zones around the paper discs impregnated with BA and PA.
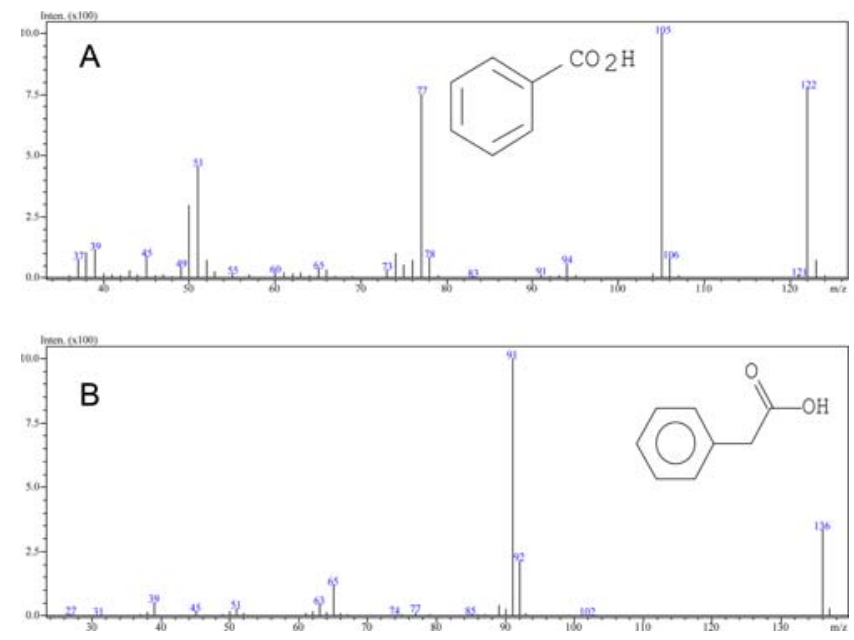

Fig. 4. GC-EI-MS spectra and structures of benzoic acid (A) and phenylacetic acid (B) isolated from the culture of B. cepacia MPC-7. 


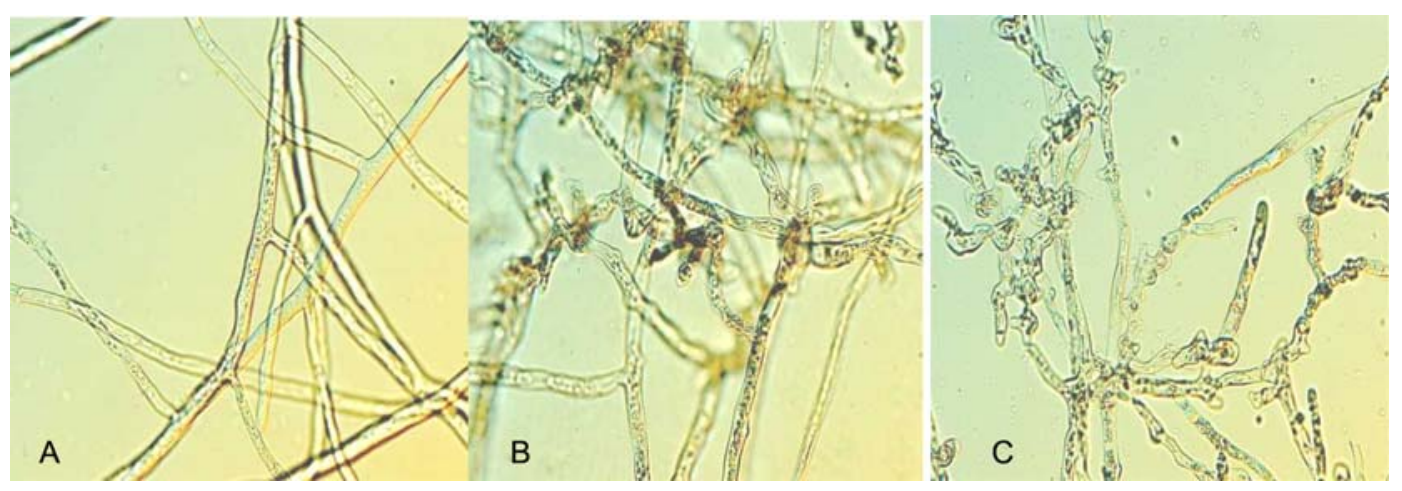

Fig. 5. Hyphal morphology of $P$. capcisi grown in potato dextrose broth treated with $250 \mathrm{ppm}$ of methanol (A), benzoic acid (B) and phenylacetic acid (C) after incubation for $24 \mathrm{~h}$ at $30^{\circ} \mathrm{C}$

Similar to the antibacterial activity, both BA and PA consistently showed a broad spectrum of antifungal activities. Complete inhibitions to the growth of $B$. cinerea, $D$. bryoniae, F. oxysporum f. sp gladioli, P. capsici, P. aphanidermatum and $R$. solani AG-1 were observed in media containing 500 ppm benzoic acid. Furthermore, PA had perfect growth inhibition over $P$. capsici, $P$. aphanidermatum and $R$. solani AG-1. However, the A. brassicicola seemed to be relatively tolerant to both compounds and showed a moderate level of growth inhibition (between 45 and 60\%). F. oxysporum f. sp melonis was less affected at $500 \mathrm{ppm}$ of phenylacetic acid and the lowest level of growth inhibition $(<45 \%)$ was recorded.

Destruction of $P$. capsici hyphal morphology by antifungal compounds. Both 250 ppm of BA and PA affected the normal growth of $P$. capsici. Through microscopic studies, the deformation of fungal hyphae treated with both compounds was quite distinct from the normal one after incubation for $24 \mathrm{~h}$ at $30^{\circ} \mathrm{C}$ (Fig. 5). Moreover, the architecture and angle of hyphal branching were also severely altered. The reaction of BA and PA to the fungal cell wall caused the hyphae to be severely distorted, deformed and somewhat enlarged at the tip while the normal shape and

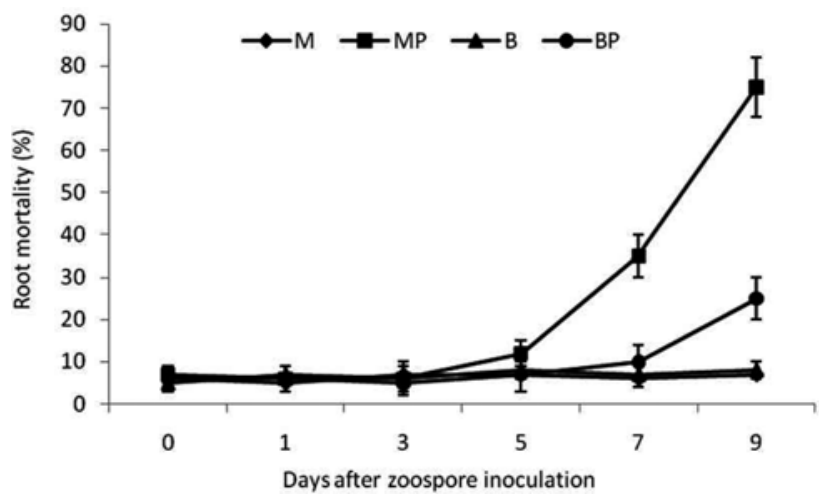

Fig. 6. Changes of root mortality in pepper as influenced by culture broth medium only (M), M + P. capsici (MP), MPC-7 cultured broth $(\mathrm{B})$ and $\mathrm{B}+P$. capsici $(\mathrm{BP})$. Mean values are from 3 replicates. Mean values were from three replicates $( \pm \mathrm{SD})$.

branching was maintained in control (Fig. 5C).

Biocontrol of $P$. capsici by B. cepacia MPC-7 on pepper in vivo. The root mortality of pepper plants did not vary among treatments during the earlier days after the inoculation of Phytophthora zoospores. Notably at fifth day, the pathogenic attack of zoospore was first conspicuous due to

Table 2. Root and shoot characteristics, $\mathrm{N}$ and $\mathrm{P}$ concentrations of pepper plants at 9 days after inoculation of $P$. capsici zoospore suspension

\begin{tabular}{|c|c|c|c|c|c|c|c|c|}
\hline \multirow[b]{2}{*}{ Treatment } & \multicolumn{3}{|c|}{ Shoot } & \multicolumn{3}{|c|}{ Root } & \multirow{2}{*}{$\begin{array}{l}\text { Plant Height } \\
(\mathrm{cm})\end{array}$} & \multirow{2}{*}{$\begin{array}{l}\text { Leaf Area } \\
\left(\mathrm{cm}^{2}\right)\end{array}$} \\
\hline & $\begin{array}{l}\text { Dry Weight } \\
(\mathrm{g})\end{array}$ & $\begin{array}{l}\text { N Conc } \\
(\%)\end{array}$ & $\begin{array}{l}\text { P Conc } \\
(\%)\end{array}$ & $\begin{array}{l}\text { Dry Weight } \\
(\mathrm{g})\end{array}$ & $\begin{array}{l}\text { N Conc } \\
(\%)\end{array}$ & $\begin{array}{l}\text { P Conc } \\
(\%)\end{array}$ & & \\
\hline M & $1.89 \pm 0.2 b$ & $2.33 \pm 0.4 b$ & $1.75 \pm 0.1 \mathrm{a}$ & $0.16 \pm 0.02 \mathrm{a}$ & $1.64 \pm 0.2 \mathrm{a}$ & $1.75 \pm 0.1 b$ & $37.56 \pm 2.5 c$ & $716.73 \pm 32 b$ \\
\hline MP & $1.37 \pm 0.1 \mathrm{c}$ & $2.36 \pm 0.3 b$ & $1.71 \pm 0.1 \mathrm{a}$ & $0.14 \pm 0.02 \mathrm{a}$ & $1.74 \pm 0.1 \mathrm{a}$ & $1.53 \pm 0.2 \mathrm{c}$ & $36.43 \pm 2.8 \mathrm{c}$ & $476.47 \pm 24 c$ \\
\hline B & $2.21 \pm 0.2 \mathrm{a}$ & $2.6 \pm 0.2 \mathrm{a}$ & $1.87 \pm 0.2 \mathrm{a}$ & $0.20 \pm 0.01 \mathrm{a}$ & $1.77 \pm 0.1 \mathrm{a}$ & $1.92 \pm 0.3 \mathrm{a}$ & $43.28 \pm 3.2 \mathrm{a}$ & $778.08 \pm 28 \mathrm{a}$ \\
\hline BP & $2.07 \pm 0.2 \mathrm{ab}$ & $2.4 \pm 0.3 b$ & $1.8 \pm 0.1 \mathrm{a}$ & $0.18 \pm 0.01 \mathrm{a}$ & $1.78 \pm 0.1 \mathrm{a}$ & $1.87 \pm 0.2 \mathrm{ab}$ & $40.08 \pm 3.1 b$ & $734.71 \pm 33 b$ \\
\hline
\end{tabular}

M, culture broth medium only; MP, M + P. capsici; B, MPC-7 cultured broth; BP, B + P. capsici; each value is mean of three pepper plants from three replicates, different letters within each column $(\mathrm{F}>4, \mathrm{df}=3,8, \mathrm{P}<0.05)$ are significantly different according to LSD test. 
a sudden increase of root mortality in MP. The increase was very rapid at day 7 and 9 while the control plants in $\mathrm{M}$ and $\mathrm{B}$ did not show any increase in root mortality (Fig. 6). In spite of zoospore inoculation, the root death of plants in treatment BP was nullified and the root mortality was reduced as much as $50 \%$ compared to that of MP. Consequently, plants in treatment MP wilted as early as five days after zoospore inoculation while those in BP showed no wilting. The plants in BP had similar growth performance with those in $\mathrm{M}$ which did not receive any zoospore inoculation. On the other hand, plants in B had the greatest leaf area, higher dry weight; shoot $\mathrm{N}$ and root $\mathrm{P}$ concentrations and greater leaf area than those in $\mathrm{M}$ and MP treatments (Table 2). The plants in BP also had higher root $\mathrm{P}$, shoot dry weight and greater leaf area than those in MP although both received $P$. capsici zoospore suspension. At the end of the experiment, the plants in B and BP were taller than the plants in M and MP.

\section{Discussion}

The hydroxyapatite agar media has been previously used to screen the phosphate solubilization bacteria for the appearance of clear zone on the surface of media (Kim et al., 1997a; Kim et al., 1997b). Accordingly, B. cepacia MPC-7 initially selected as strongest chitinolytic bacterial strain was considered as phosphobacteria because it also solubilized the insoluble phosphate present in the hydroxyapatite agar media. Generally, the mechanism of mineral phosphate solubilization by PSB strains is associated with the release of low molecular weight organic acids (Kim et al., 1997a). HPLC chromogram showed two major peaks which were identified as gluconic acid and 2-Keto gluconic acid having similar retention times with those of our previous reports ( $\mathrm{Na}$ et al., 2009; Park et al., 2005). Quantitative analysis showed that the concentration of soluble $\mathrm{P}$ increased with decrease in $\mathrm{pH}$ of culture medium (Fig. 2). This decrease in $\mathrm{pH}$ was related to the production of gluconic acid and 2-KGA (Fig. 1). The concentration of 2KGA increased gradually with incubation time and it seemed to be further oxidization of gluconic acid to 2KGA. Similar trend of changes in 2-KGA was also found in our previous report (Hwangbo et al., 2003) in which Enterobacter intermedium possessed a strong ability to solubilize insoluble phosphate, and oxidized glucose to gluconic acid and sequentially to $2-\mathrm{KGA}$. It is also in agreement with Ta et al. (2006) who reported the production of gluconic acid and 2-KGA by B. cepacia strain caused the solubilization of tricalcium phosphate. The mechanism of $\mathrm{P}$ solubilization has been previously reported by Rodriguez and Fraga (1999) as gluconic acid diffuses freely outside of the cells and might release high amounts of soluble $\mathrm{P}$ from insoluble $\mathrm{P}$, by supplying both protons and cation complexing organic acid anions. These organic acids may reduce $\mathrm{pH}$ and act as chelating agents, forming complexes with $\mathrm{Ca}, \mathrm{Fe}$, or $\mathrm{Al}$, and thereby releasing the phosphates to solution (Viruel et al., 2011). Finally, the insoluble form of phosphorous is converted into soluble monobasic $\left(\mathrm{H}_{2} \mathrm{PO}_{4}\right)$ and dibasic $\left(\mathrm{HPO}_{4}{ }^{2-}\right)$ ions, a process referred to as mineral phosphate solubilization. This leads to an increase in the availability of phosphorous to plants and in turn the plant uptake (Gyaneshwar et al., 2002). Notably, the maximum solubilization of $\mathrm{P}$ observed at $4^{\text {th }}$ day of incubation was coincided with the maximum $\mathrm{pH}$ decline of culture broth (Fig. 3). This result was further strengthened by Chen et al. (2006) who reported that bacterial strains such as Arthrobacter sp. and Serratia marcescens which synthesized maximum number of organic acids showed maximum decline in $\mathrm{pH} 4.9$ with higher levels of $\mathrm{P}$ solubilization.

The MPC-7 produced benzoic acid in CB media. Rarely, one report about production of BA in minimum mineral medium by $B$. cepacia was available (Philippe et al., 2001). The halo zone test and radial growth inhibition tests, 500 ppm of BA showed very strong antimicrobial activity against yeast, all bacterial and most fungal pathogens tested. The mechanism of inhibition to the growth of Saccharomyces cerevisae was previously reported by Krebs et al. (1983) as the benzoic acid inhibited the growth by lowering the intracellular $\mathrm{pH}$, which inhibited glycolysis, especially by inhibition of phosphofructokinase. Although the mechanism of its inhibition to bacteria was not known yet, lipophilic acid such as BA is known to inhibit the active uptake of some amino and oxoacids in E. coli and $B$. subtilis (Russell and Chopra, 1996).

PA was isolated from other micro-organisms such as Pseudomonas sp. (Jae et al., 1999), Streptomyces humidus (Hwang et al., 2001) and Bacillus licheniformis (Kim et al., 2004). However, this is the first report about production of PA by $B$. cepacia. In this study, 500 ppm PA consistently showed strong antimicrobial activity against all bacteria, and a varying level of inhibition against all fungal pathogens tested (Table 1). The mode of action of phenyl acetic acid on all stages of the life cycle of $P$. capsici, including zoospore motility, zoospore germination, and mycelia growth may be connected with impairment of the energy generation system (Lee et al., 2004). Our finding is in agreement with Kim et al. (2004) who reported that the BA and PA produced by Bacillus licheniformis showed strong antimicrobial properties against several bacteria, fungi and yeast.

By microscopic observation, the fungal cell walls of $P$. capsici were severely affected by $250 \mathrm{pm}$ of BA and PA. Each compound might be presumably associated with biochemical changes leading to structural modification of 
$P$. capsici cell walls. As a consequence, the normal morphology of hyphae was distinctly destroyed and the architecture of branching pattern was severely disturbed resulting to abnormality of hyphae (Fig. 5).

The biocontrol potential of MPC-7 was demonstrated in pot trial. As shown in Fig. 6, the root mortality of plants treated with MPC-7 was significantly lower than the controls. The result demonstrated that the drenching of rhizosphere by MPC-7 and earlier root colonization prevented the invasive zoospore infection of the soil borne pathogen $P$. capsici. The production of antimicrobial compounds such as benzoic acid and phenyl acetic acid by MPC-7 might play a key role of disease protection by inhibiting the growth of fungal hyphae (Fig. 5). Moreover, these antibiotics might individually or synergistically interact to prevent zoospore germination or directly destroy them. Therefore, the hyphal growth was supposed to be prevented by these antibiotics from the beginning of the pathogen lifecycle. This finding was supported by Lee et al. (2004) who reported that the concentration of $10 \mu \mathrm{gml}^{-1}$ of phenylacetic acid was sufficient to lyze most of $P$. capsici zoospores. In our current study, growth of pepper plants treated with bacterial cultures was significantly enhanced and resulted in excellent protection from disease. This elegant result demonstrated that drenching of root zone with antagonistic bacteria would be a very practical method and it can be efficiently applied in field through drip irrigation facilities.

As shown in Table 2, the highest $\mathrm{P}$ concentration in roots treated with MPC-7 pinpointed the potential of this strain to enhance available $\mathrm{P}$. The subsequent higher uptake of $\mathrm{P}$ by those plants might contribute better growth through greater photoperception and photosynthetic efficiency that finally increased the dry matter assimilation, shoot $\mathrm{N}$ concentration and plant height (Table 2). Moreover, the significance of greater leaf area, dry weight and height of plants treated with MPC-7 may also be supplemented by the production of phenylacetic acid which has been known as a growthand development-promoting compound in maize (Sarwar and Frankenberger, 1995) and a natural auxin in the shoots of higher plants, such as barley, corn, tobacco and tomato (Wightman and Lighty, 1982). In conclusion, the present study demonstrated that $B$. cepacia MPC-7 is considered as a candidate for the biological fertilizer as well as antimicrobial agent for pepper plants.

\section{Acknowledgments}

The authors wish to express their gratitude to the Institute of Planning and Evaluation for Technology in Food, Agriculture, Forestry and Fisheries for the financial support to this study.

\section{References}

Babu, B. S., Pandravada, S. R., Prasada Rao, R. D. V. J., Anitha, K., Chakrabarty, S. K. and Varaprasad, K. S. 2011. Global sources of pepper genetic resources against arthropods, nematodes and pathogens. Crop Prot. 30:389-400.

Bajpai, P. D. and Rao, W. B. S. 1971. Phosphate solubilizing bacteria II. Extracellular production of organic acids by selected bacteria solubilizing insoluble phosphates. Soil Sci. Plant Nutr. 17:44-45.

Baldani, V. B., Alvarez, I., Baldani, I. and Dobereiner, J. 1986. Establishment of inoculated Azospirillum spp. in the rhizosphere and in the roots of field grown wheat and sorghum. Plant Soil 90:35-46.

Bartlett, D. W., Clough, J. M., Godwin, J. R., Hall, A. A., Hamer, M. and Parr-Dobrzanski, B. 2002. The strobilurin fungicides. Pest Manag. Sci. 58:649-662.

Booth, I. R. and Kroll, R. G. 1989. The preservation of foods by low $\mathrm{pH}$. In: Mechanisms of action of food preservation procedures, ed. by G. W. Gould, pp. 119-160. Elsevier Applied Science, London, UK.

Burr, T. J., Schroth, M. N. and Suslow, T. 1978. Increased potato yields by treatment of seedpieces with specific strains of Pseudomonas fluorescens and Pseudomonas putida. Phytopathology 68:1377-1383.

Chae, D. H., Jin, R. D., Hwangbo, H., Kim, Y. W., Kim, Y. C., Park, R. D., Krishnan, H. B. and Kim, K. Y. 2005. Control of late blight (Phytophthora capsici) in pepper plant with a compost containing multitude of chitinase-producing bacteria. Biocontrol 51:339-335.

Chapman, H. D. and Pratt, P. F. 1961. Methods of analysis for soils, plants and waters. University of the Califonia, Riverside, USA. 309 pp.

Chen, Y. P., Rekha, P. D., Arun, A. B., Shen, F. T., Lai, W. A. and Young, C. C. 2006. Phosphate solubilizing bacteria from subtropical soil and their tricalcium phosphate solubilizing abilities. Appl. Soil Ecol. 34:33-41.

Chilpa, R. R., Vazquez, I. R. Q., Estrada, M. J., Ocana, A. N. and Hernandez, J. C. 1997. Antifungal activity of selected plant secondary metabolites against Coriolus versicolor. J. Tropic. Forest Products 3:110-113.

Gyaneshwar, P., Kumar, G., Parekh, L. and Poole, P. 2002. Role of soil microorganisms in improving $\mathrm{P}$ nutrition of plants. Plant Soil 245:83-93.

Hwang, B. K. and Kim, D. H. 1995. Phytophthora blight of pepper and its control in Korea. Plant Dis. 79:221-227.

Hwang, B. K., Lim, S. W., Kim, B. S., Lee, J. Y. and Moon, S. S. 2001. Isolation and in vivo and in vitro antifungal activity of phenylacetic acid and sodium phenylacetate from Streptomyces humidus. Appl. Environ. Microbiol. 67:3739-3745.

Hwangbo, H., Park, R. D., Kim, Y. W., Rim, Y. S., Park, K. H., Kim, T. H., Suh, J. S. and Kim, K. Y. 2003. 2-Ketogluconic acid production and phosphate solubilization by Enterobacter intermedium. Curr. Microbiol. 47:87-92.

Illmer, P. and Schinner, F. 1992. Solubilization of inorganic phosphates by microorganisms isolated from forest soil. Soil Biol. 
Biochem. 24:389-395.

Kang, J. G., Kim, S. T. and Kang, K. Y. 1999. Production of the antifungal compound phenylacetic acid by antagonistic bacterium Pseudomonas sp. Agri. Chem. Biotechnol. 42:197-201.

Kim, K. D., Nenec, S. and Musson, G. 1997. Control of Phytophthora root and crown rot of bell pepper with composts and soil amendments in the green house. Appl. Soil Ecol. 5:169-179.

Kim, K. Y., Jordan, D. and Krishnan, H. B. 1997a. Rahnella aquatilis, a bacterium isolated from soybean rhizosphere, can solubilize hydroxyapatite. FEMS Microbiol. Lett. 153:273-277.

Kim, K. Y., McDonald, G. A. and Jordan, D. 1997b. Solubilization of hydroxyapatite by Enterobacter agglomerans and cloned Escherichia coli in culture medium. Biol. Fertil. Soils 24:347-352.

Kim, K. Y., Jordan, D. and McDonald, G. A. 1998. Effect of phosphate solubilizing bacteria and vesicular-arbuscular mycorrhizae on tomato growth and soil microbial activity. Biol. Fertil. Soils 26:79-87.

Kim, Y., Cho, J. Y., Kuk, J. H., Moon, J. I., Cho, J. I., Kim., Y. C. and Park, K. H. 2004. Identification and antimicrobial activity of phenylacetic acid produced by Bacillus licheniformis isolated from fermented soybean, Chungkook-Jang. Curr. Microbiol. 48:312-317.

Kloepper, J. W., Lifshitz, R. and Schroth, M. N. 1988. Pseudomonas inoculants to benefit plant production. In: ISI Atlas of Science, Animal and Plant Sciences, pp. 60-64. Institute for Scientific Information, Philadelphia, USA.

Knievel, D. P. 1973. Procedure for estimating ratio of live to dead root dry matter in root core samples. Crop Sci. 13:124-126.

Koumoutsi, A., Chen, X. H., Henne, A., Liesegang, H., Gabriele, H., Franke, P., Vater, J. and Borris R. 2004. Structural and functional characterization of gene clusters directing non-ribosomal synthesis of bioactive lipopeptides in Bacillus amyloliquefaciens strain FZB42. J. Bacteriol. 186:1084-1096.

Krebs, H. A., Wiggins, D., Stubbs, M., Sol, A. and Bedoya, F. 1983. Studies on the antifungal action of benzoate. Biochem. J. 214:657-663.

Lamour, K. H. and Hausbeck, M. K. 2003. Effect of crop rotation on the survival of Phytophthora capsici in Michigan. Plant Dis. 87:841-845.

Lee, S. J., Cho, J. Y., Cho, J. I., Moon, J. H., Park, K. D., Lee, Y. J. and Park, K. H. 2004. Isolation and characterization of antimicrobial substance macrolactin A produced from Bacillus amyloliquefaciens $\mathrm{CHO} 104$ isolated from soil. J. Microbiol. Biotech. 14:525-531.

Leyval, C. and Berthelin, J. 1989. Interactions between Laccaria laccata, Agrobacterium radiobacter and beech roots: Influence on $\mathrm{P}, \mathrm{K}, \mathrm{Mg}$ and $\mathrm{Fe}$ mobilization from minerals and plant growth. Plant Soil 117:103-110.

Li, W., Roberts, D. P., Dery, P. D., Meyer, L. F., Lohrke, S., Lumsden, R. D. and Hebbar, K. P. 2002. Broad spectrum anti-biotic activity and disease suppression by the potential biocontrol agent Burkholderia ambifaria BC-F. Crop Prot. 21:129-135.

Loper, J. E. and Gross, H. 2007. Genomic analysis of antifungal metabolite production by Pseudomonas fluorescens Pf-5. Eur. J. Plant Pathol. 119:265-278.
Moghimi, A., Tate, M. E. and Oades, I. M. 1978. Characterization of rhizosphere products especially 2-ketogluconic acid. Soil Biol. Biochem. 10:283-287.

Na, J. H., Choi, J. H., Jin, R. D., Ko, H. S., Park, R. D. and Kim, K. Y. 2009. Phosphate solubilization and plant growth promotion by crop associated bacteria. Korean J. Soil Sci. Fert. 42:29-36.

Olsen, S. R. and Sommers, L. E. 1982. Phosphorus. In: Method of soil analysis part 2, chemical and microbial properties, ed. by A. L. Page, R. H. Miller and D. R. Keeney, pp. 403-430. American Society of Agronomy, Madison, USA.

Ortega-Morales, B. O., Ortega-Morales, F. N., Reyna, J. L., De la Rosa-García, S. C., Hernández, A. M. and Montero, J. M. 2009. Antagonism of Bacillus spp. isolated from marine biofilms against terrestrial phytopathogenic fungi. Mar. Biotechnol. 11:375-383.

Park, B. K., Na, J. H., Hoon, H. B., Lee, I. J., Kim, K. Y. and Kim, Y. W. 2005. Effect of phosphate bio fertilizer produced by Enterobacter intermedium on rhizosphere soil properties and lettuce growth. Korean J. Soil Sci. Fert. 38:15-24.

Philippe, G., Vega, D. and Bastid, J. 2001. Microbial hydrolysis of methyl aromatic esters by Burkholderia cepacia isolated from soil. FEMS Microbiol. Ecol. 37:251-258.

Patel, D. K., Archana, G. and Kumar, G. N. 2008. Variation in the nature of organic acid secretion and mineral phosphate solubilization by Citrobacter sp. DHRSS in the presence of different sugars. Curr. Microbiol. 56:168-174.

Paul, D. and Sarma, Y. 2006. Antagonistic effects of metabolites of Pseudomonas fluorescens strains on the different growth phases of Phytophthora capsici, foot rot pathogen of black pepper (Piper nigrum L.). Arch. Phytopathol. Plant Protect. 39:311-314.

Ren, J. H., Ye, J. R., Liu, H., Xu, X. L. and Wu, X. Q. 2011. Isolation and characterization of a new Burkholderia pyrrocinia strain JK-SH007 as a potential biocontrol agent. World $J$. Microbiol. Biotechnol. 27:2203-2215.

Richardson, A. E. 2001. Prospects for using soil microorganism to improve the acquisition of phosphate by plant. Aust. J. Plant Physiol. 28:897-906.

Ristaino, J. B. and Johnston, S. A. 1999. Ecologically based approaches to management of Phytophthora blight on bell pepper. Plant Dis. 83:1080-1089.

Rodriguez, H. and Fraga, R. 1999. Phosphate solubilizing bacteria and their role in plant growth promotion. Biotechnol. Adv. 17: 319-339.

Rosenberger, D. A. and Meyer, F. W. 1981. Post-harvest fungicides for apples: development of resistance to benomyl, vinclozolin and iprodione. Plant Dis. 65:1010-1013.

Russell, A. D. and Chopra, I. 1996. Understanding antibacterial action and resistance. 2nd ed. Ellis Horwood, London, UK. 292 pp.

Sivan, A. and Chet, I. 1992. Microbial control of plant diseases. In: Environmental Microbiology, ed. by R. Mitchell, pp. 335354. Wiley-Liss, New York, USA.

Sopheareth, M., Lee, S. J., Hwangbo, H., Kim, Y. W., Park, K. H., Cha, G. S., Park, R. D. and Kim, K. Y. 2006. Isolation and 
characterization of antifungal substances from Burkholderia sp. culture broth. Curr. Microbiol. 53:358-364.

Sperber, J. I. 1957. Solution of mineral phosphates by soil bacteria. Nature 180:994-995.

Ta, F. L., Hsin, I. H., Shen, F. T. and Young, C. C. 2006. The protons of gluconic acid are the major factor responsible for the dissolution of tricalcium phosphate by Burkholderia cepacia CC-A174. Bioresource Technol. 97:957-960.
Viruel, E., Lucca, M. E. and Sineriz, F. 2011. Plant growth promotion traits of phosphobacteria isolated from Puna, Argentina. Arch. Microbiol. 193:489-496.

Wang, H. X., Lui, F. and Ng, T. B. 2001. Examination of pineal indoles and 6-methoxy-2-benzoxaolinone for antioxidant and antimicrobial effects. Comp. Biochem. Physiol. C Toxicol. Pharmacol. 130:379-388. 